\title{
Application of biological safety index in two Japanese watersheds using a bioassay battery
}

\author{
Dongbin Wei ${ }^{\mathrm{a}, \mathrm{b}, *}$, Zhifen Lin $^{\mathrm{c}}$, Takashi Kameya ${ }^{\mathrm{b}}$, Kohei Urano ${ }^{\mathrm{b}}$, Yuguo Du $^{\mathrm{a}}$ \\ a Research Center for Eco-Environmental Sciences, Chinese Academy of Sciences, 18 Shuangqing Road, Haidian District, Beijing 100085, PR China \\ ${ }^{\mathrm{b}}$ Graduate School of Environment and Information Science, Yokohama National University, Yokohama 240-8501, Japan

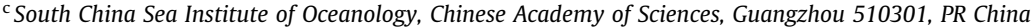

\section{A R T I C L E I N F O}

\section{Article history:}

Received 9 January 2008

Received in revised form 10 April 2008

Accepted 16 April 2008

Available online 4 June 2008

\section{Keywords:}

Biological safety

Water quality index

Bioassay

Watershed

\begin{abstract}
A B S T R A C T
In order to integratedly evaluate the biological safety as a water quality index, an assessment method based on three toxicity tests (algae growth inhibition, daphnia immobilization and larval fish toxicity) was developed. In this study, the developed method was used to screen, evaluate and rank the biological safety of small rivers near agricultural, industrial and residential areas. Twenty-seven representative water samples were collected from the Kaname River watershed and the Hinata River watershed in Kanagawa Prefecture, Japan. The results indicated that (1) the biological safety of water from the Hinata River ranked much higher than those from the Suzu River and the Shibuta River due to less human activities, (2) the biological safety from outlets of paddy fields ranked much worse than those from point source discharges of toxic pollutants, (3) the use of pesticides significantly affected the water quality of nearby small rivers and ditches during the pesticide application season, (4) the effects of different kinds of pesticides could successfully be classified using one toxicity test component of the bioassay battery, and (5) there was no significant quantitative relationship between the toxicity and dissolved organic carbon (DOC) for the studied water samples. The toxicities of water samples in this study were in agreement with the concentrations of pesticides determined with chemical methods by other researchers, which demonstrated that the developed assessment method was reliable to screen site contaminated with organic chemicals for priority management.
\end{abstract}

(c) 2008 Elsevier Ltd. All rights reserved.

\section{Introduction}

Due to limited freshwater supply in the world, protecting the integrity of water resources has become one of the most important environmental challenges for the 21 st century. In addition, there are increasing concerns for potential adverse effects on human and ecological health resulting from production, use, and disposal of numerous chemicals that were intended for improving human welfare (Daughton and Ternes, 1999). Research has shown that many such compounds can enter the environment, disperse, and persist to a greater extent than originally anticipated. Some compounds, such as pesticides, are intentionally released in their applications. Others, such as industrial by-products, are released through regulated and unregulated industrial discharges to water bodies. Household chemicals, pharmaceuticals, and other consumables as well as biogenic hormones are released directly to the environment after passing through wastewater treatment pro-

\footnotetext{
* Corresponding author. Address: Research Center for Eco-Environmental Sciences, Chinese Academy of Sciences, 18 Shuangqing Road, Haidian District, Beijing 100085, PR China. Tel.: +86106284 9441; fax: +861062923563.

E-mail address: weidb@rcees.ac.cn (D. Wei).
}

cesses that were often not designed to remove them from the effluent (Halling-Sorensen et al., 1998). As a result, there are a wide variety of pollution sources to enter and persist in environmental waters.

Hazard or risk assessments of polluted environmental elements are usually conducted with physicochemical measurements; however, chemical analysis alone may not be sufficient for assessing biological safety (Fernandez et al., 2005). Also, it is not possible to include physicochemical analysis of all the chemical pollutants contributing to toxicity in addition to their synergistic or antagonistic interactive effects (Juvonen et al., 2000). However, biological toxicity tests are useful tools for integrating the effects of all the bio-available contaminants and of their interaction (Hernando et al., 2005).

For refined evaluation of environmental risks, the use of a set of tests on species at different levels of biological organization and of biological approaches to complement physico-chemical analyses has been recommended (Bispo et al., 1999; Bekaert et al., 1999; Rila and Eisentraeger, 2003; Fernandez et al., 2005). For example, bioassays have been applied to evaluate the toxicity of the water sample with three most frequently used aquatic ecotoxicity tests: acute fish lethal test, acute daphnia immobilization test and 
chronic algae growth inhibition test (Ferard and Ferrari, 2005). However, in implementing a sound water quality management, a reasonable evaluation index and simple assessment tool for characterizing the hazard of pollutants on aquatic organisms will be useful but is lacking, because each toxicity test is measured with different endpoint, and it is hard to compare and integrate these different toxicity test endpoints as one index. Aiming at the pesticides pollution, USGS (US Geological Survey) developed Pesticide Toxic Index (PTI) in 2001, a variation of a risk-based scoring system described by Kimerle et al. (1997), for protecting freshwater aquatic organisms from the pesticide pollution, which calculated the sum of toxicity quotients for each pesticide compound measured in a stream (Munn and Gilliom, 2001). However, the PTI has its limitations, for example, the PTI is based on a simplifying assumption that pesticide toxicity is additive and there is no chemical interaction (synergism, antagonism), which may not be the case in the environment (Munn and Gilliom, 2001). A simple toxicity classification system with five microbiotests for natural waters and wastewaters was proposed (Personne et al., 2003), which ranked water or wastewater in five classes of increasing hazard/toxicity class: no acute hazard, slight acute hazard, acute hazard, high acute hazard and very high acute hazard. Because the scoring system adopted five acute toxicity tests, the long-term hazard of pollutants to aquatic organisms is difficult to estimate although the system is user friendly and visually appealing.

Recently, Wei (the correspondent author) and his coworkers proposed a new biological safety evaluation method, three widely used species, algae (Selenustrum capricornutum), daphnia (Daphnia magna) and fish (Oryzias latipes larvae) belonging to three trophic levels in aquatic ecosystem, were selected as a test set to measure the bio-toxicity of water sample. Maximum exposure concentrations for algae, daphnia and fish tests were respectively designed as $10-, 50$ - and 50 -fold of river water-based on a simplification of toxicity extrapolation method developed by EU. A novel assessment index "toxicity score" of 1, 2, 3 and 4 with 1 being the safest was established for normalizing the toxicity effects. Toxicity score was determined according to the highest exposure concentration where adverse ecotoxicological effects could not be observed, and a triangle figure was designed to visually describe the toxicity scores of three toxicity tests. Finally, in order to conveniently evaluate the biological safety of environmental water, an integrated assessment index "bio-safety rank" (BSR) was established and determined according to the safety scores of the three tests, and with the index BSR, water sample could be ranked as A, B, C or D with A being the safest (Wei et al., 2006). This approach based on the risk extrapolation of chemical pollutants overcame some limitations of previous toxicity classification systems, such as using direct toxicity tests to describe the objective biological effects of mixed compounds, but not assumed as additive toxicity effect, which appears to be very promising in solving some of the issues facing water managers by providing chronic predictable biological safety of water quality using short-term toxicity tests.

The Kaname River is one of the principal rivers in Kanagawa Prefecture, Japan, which mainly consists of several large tributaries such as the Suzu River, the Shibuta River and so on. The Hinata River is a small branch of the Sagami River in Kanagawa Prefecture, Japan. Along the mainstreams and tributaries of studied rivers, there are several different types of land uses, such as residential, agricultural and industrial areas where some toxic chemicals (e.g. pesticides, industrial products) have been discharged into nearby rivers during human activities. Recent studies reported that the loading rates of thiobencarb, mefenacet and simetryne in the Kaname River watershed was 82, 35 and 38 kg/yr (Otsuka and Kawahara, 2005); however, their toxic effects on the aquatic organisms in the river water nearby agricultural fields are not understood and pose serious concerns. In this study, the developed toxicity-based evaluation methods were applied to screen the biological safety of river water, and to evaluate the effects of toxic pollutants on water quality due to human activities.

\section{Materials and methods}

\subsection{Sampling}

In Japan, many farmers are part-time farmers and work in office or factory during weekdays, parts of paddy fields are managed under spillover irrigation, and the pesticides spraying is usually conducted on weekends. Therefore, one water sample per site was taken daily for one week after the first spraying of pesticides within the study areas. The sampling sites were selected at $50 \mathrm{~m}$ downstream from the drainage outlet or sewage outfall, and water samples were taken from three points along each sampling transect (left, right and center) of river, except for narrow ditch where only one point was used. The three samples were then mixed to provide a 41 composite sample. During the months of April-August in 2005, a total of 189 water samples were collected from seven sites in both tributaries and mainstreams of the Kaname River and the Hinata River within Kanagawa Prefecture as shown in Fig. 1. The figure also showed the distribution of catchments and the coverage of sewerage services. Based on topography and land-use characteristics of the catchments, the sampling sites fell into three areas as described below.

The first area was located on the upper reach of the Hinata River, where the number of residents and industries was relatively low, and only had some sporadic paddy fields. Three sampling sites (A, B and C) along the river were selected from upslope, downslope and in between of the two paddy fields, for evaluating the effects of agricultural drainage on water quality. The water sampling were scheduled based on agricultural planting and pesticide application periods: April 29th (blank: before planting), May 27th (at planting season), June 8th (after herbicides application), July 22nd (before insecticides application) and August 3rd (after insecticides application) in 2005.

The second area was selected from the middle reach of the Shibuta River, where a wide paddy field and some unsewered residential areas distributed along the river, and a 2-3 m width, 1-2 m depth ditch that carried river water, containing raw sewage, from a dam on the Shibuta River for irrigation and returned the water back to the river. Water samples were collected from two sites (D and E) along the ditch: upslope and downslope of the paddy field, on April 29th (blank: before planting), June 8th (after herbicides application), July 22nd (before insecticides application) and August 3rd (after insecticides application), 2005 to investigate the effects of pesticides application in paddy fields and raw sewage on the water quality of nearby small rivers and ditches.

The third area was selected from the middle reach of the Suzu River, which received an effluent discharge from a WWTP and the ditch water pumped from the river initially and used for agricultural irrigation. Water samples were collected at post-confluence point in the Suzu River (site F) and ditch receiving drainage from paddy fields (site G) on May 27th (Blank: at planting season), June 8th (after herbicides application), July 22nd (during insecticides application) and August 3rd (after insecticides application), 2005. The aim was to study the effects of pesticides application and treated municipal wastewater effluent on water quality of receiving river and ditch.

\subsection{Concentration and elution}

Water samples were collected from different time periods within the watersheds of the Kaname River and the Hinata River in Kanagawa Prefecture, where the river water were possibly polluted 


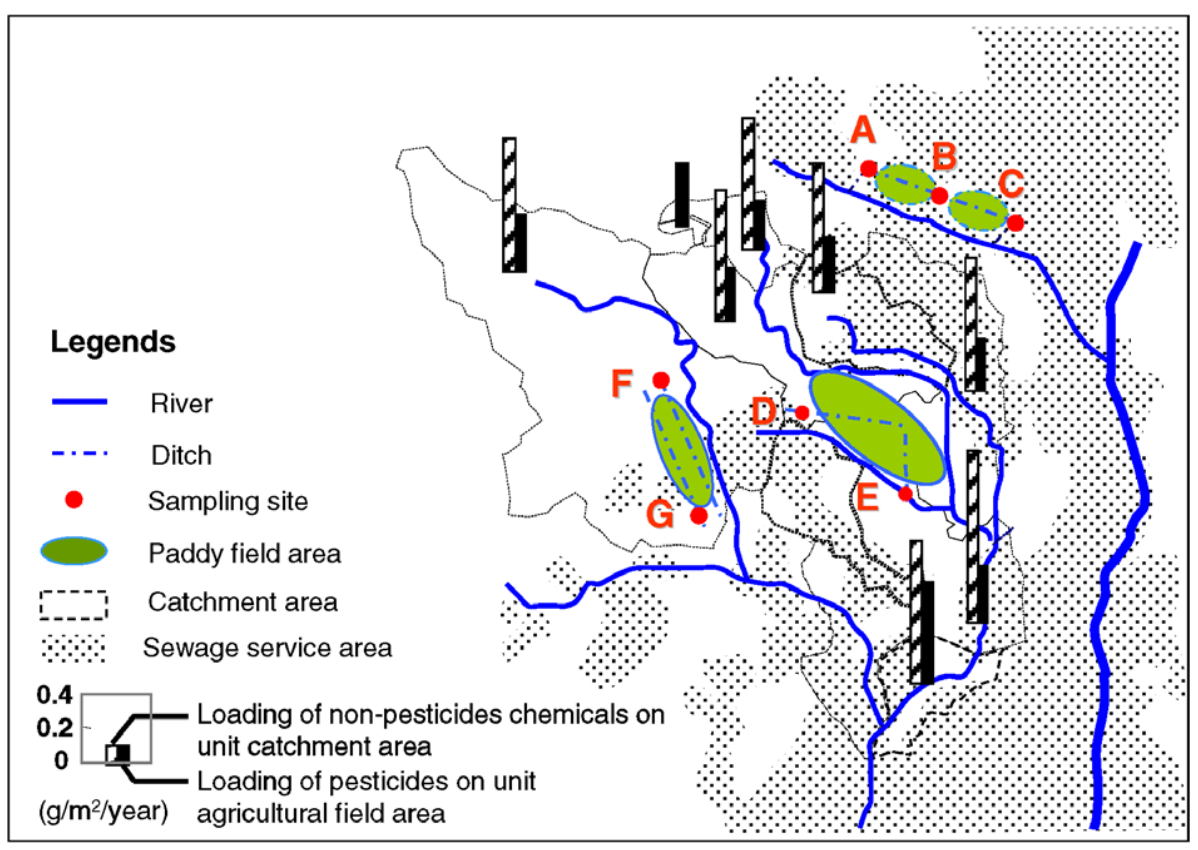

Fig. 1. Sampling sites, catchment areas, sewage service areas and chemical loadings within the study watersheds.

by pesticides or other toxic chemicals due to human activities. Each sample (4l) was filtrated with a glass fiber filter of $1.0 \mu \mathrm{m}$, followed by upflowing through two of pre-conditioned Sep-Pak ${ }^{\circledR}$ Plus PS-2 cartridge using a glass syringe pump (Sep-Pak ${ }^{\circledR}$ Concentrator Plus, Nihon Waters KK) at $20 \mathrm{ml} / \mathrm{min}$. Sep-Pak ${ }^{\circledR}$ Plus PS-2 cartridges have been reported and proved to adsorb almost all of organic micropollutants in water (Ishii et al., 2000) and have been widely applied to recover agricultural chemicals (Tanabe et al., 2000; Sudo et al., 2002; Tanabe and Kawata, 2004), endocrinedisruptors (Asakura et al., 2004), brominated flame retardants (Hasegawa and Suzuki, 2005), phenols (Hanada et al., 2002), microcystins (Kondo et al., 2000) and food preservatives (Okayama et al., 1998) from complex environmental water samples. During each elution, air was first injected manually into the cartridge with a syringe to drive out the space water. A $10 \mathrm{ml}$ volume of acetone was then pumped into each cartridge at $2.0 \mathrm{ml} / \mathrm{min}$ from opposite direction against adsorption stage for elution, and $20 \mathrm{ml}$ acetone eluate was collected in a scaled centrifuge tube. After all seven samples from the same sampling site collected during the week were completed with elution, the acetone eluates were mixed and $20 \mathrm{ml}$ was used to concentrate down to $500 \mu \mathrm{l}$ by evaporation under nitrogen gas purge at $300 \mathrm{ml} / \mathrm{min}$. Then $2.0 \mathrm{ml}$ distilled water was added to the residual solution and concentrated down to $2.0 \mathrm{ml}$ in water bath of $35^{\circ} \mathrm{C}$. The obtained 27 representative samples which were concentrated 2000 times were diluted into different concentrations and prepared as exposure solutions for toxicity tests: maximum exposure concentrations as 10,50 and 50-fold river water for algae, daphnia and larval medaka test, respectively.

\subsection{Toxicity test and evaluation method}

The stock solution of 50-fold of river water was prepared with dilution water (treated with activated carbon and ion-exchange resin), and was diluted into a series of duplicate exposure solutions. As for algae growth inhibition test, the serial exposure solutions were prepared as 2-, 4- and 10-fold of river water, the experimental conditions were: volume of exposure solution: $20 \mathrm{ml}$; initial cell density: $10^{4} / \mathrm{ml}$; shaking speed: $100 \mathrm{rpm}$; exposure duration: $72 \mathrm{~h}$; light intensity: 4000 lx; and light/dark: 24 h/0 h. A series of exposure solutions were prepared as 10-, 20- and 50-fold of river water for daphnia immobilization test, and the operational parameters were: volume of exposure solution: $20 \mathrm{ml}$; neonate age: $<24 \mathrm{~h}$ old; neonate density: 10/concentration; exposure duration: $48 \mathrm{~h}$, and light/dark: $16 \mathrm{~h} / 8 \mathrm{~h}$. The solution preparation of larval medaka toxicity test was the same as daphnia test, and the operational conditions were: volume of exposure solution: $20 \mathrm{ml}$ : larvae age: $48-$ $72 \mathrm{~h}$ old; larvae density: 10/concentration; exposure duration: $48 \mathrm{~h}$; and light/dark: $16 \mathrm{~h} / 8 \mathrm{~h}$. The highest concentration at which adverse effect cannot be observed was recorded, and their corresponding safety score along with biological safety rank (BSR) based on the worst safety score among three toxicity tests according to the approach proposed in our previous research were determined (Wei et al., 2006).

\section{Results and discussion}

The sampling sites of river water from the Hinata River, the Shibuta River and the Suzu River are shown in Figs. 2-4, respectively, in which the toxicity scores and bio-safety ranks of water quality are shown as well. In addition, dissolved organic carbon (DOC) concentrations of the water samples were measured using TOC-5000 Analyzer, and the values are listed in Table 1.

\subsection{The effects of household sewage and WWTP discharging on BSR and $D O C$}

As mentioned before, three different types of sampling areas were selected based on factors affecting background water quality. There are less residential areas and human activities within the upper reach of the Hinata River, the toxicities (all of three samples were ranked as A, being the safest) and DOCs ( $<3 \mathrm{mg} / \mathrm{l})$ of three water samples collected on April 29th were very low. However, as for the Shibuta River, the sampling sites were located on the middle reach where there were some business establishments and residential areas with $26 \%$ coverage of sewage service in March of 2004, and household raw sewages were directly discharged into the nearby river without any treatment. The test results of blank 


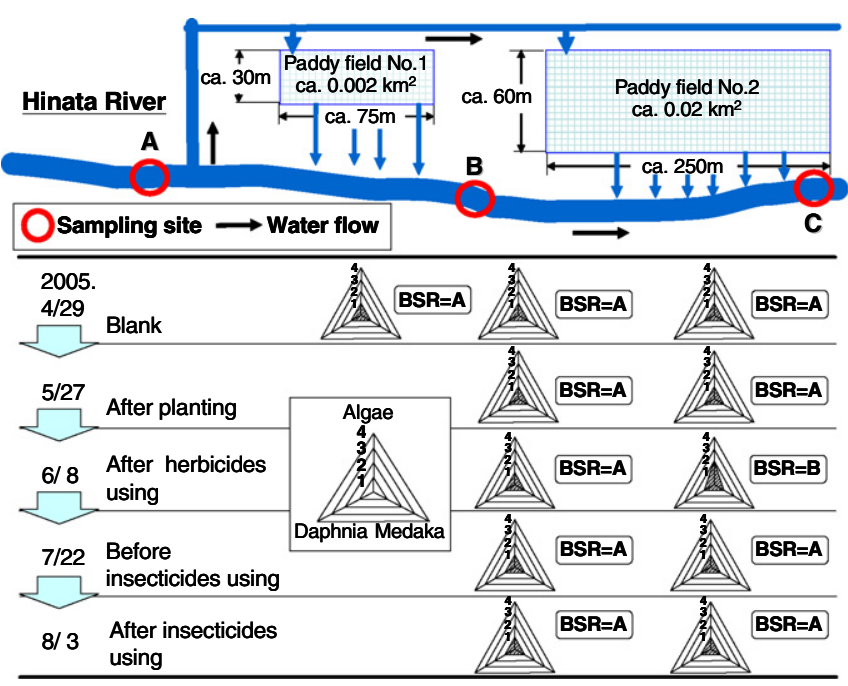

Fig. 2. The biological safety ranks at different agricultural seasons along the Hinata River.

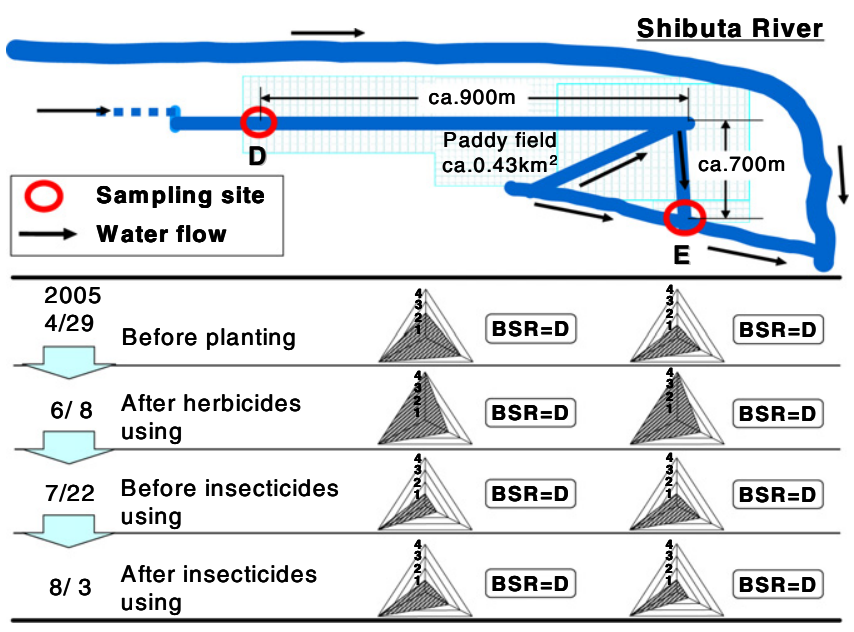

Fig. 3. The biological safety ranks at different agricultural seasons along the Shibuta River.

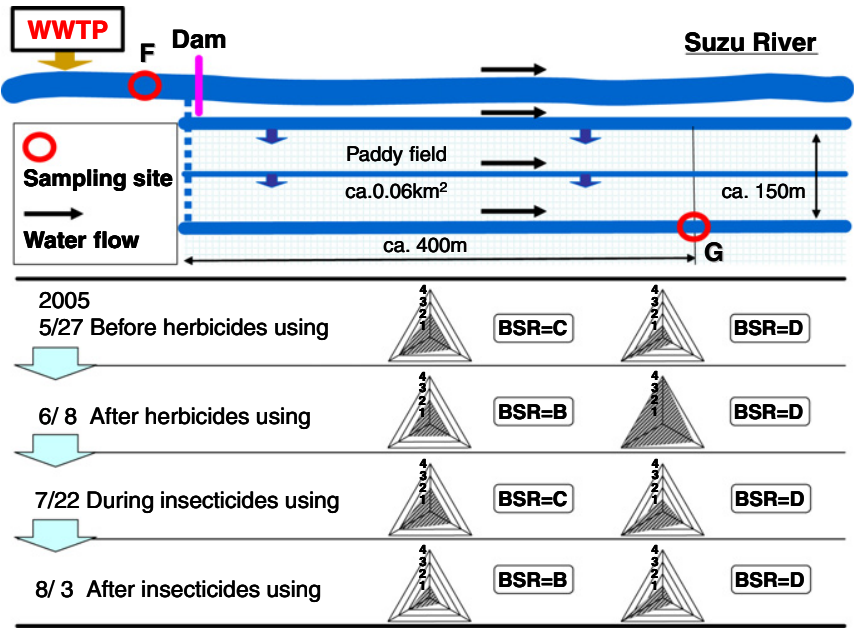

Fig. 4. The biological safety ranks at different agricultural seasons along the Suzu River. water samples collected on April 29th showed that the toxicities of the two samples (Sites D and E) were both ranked as D, being the worst, and their DOCs were 21.15 and $35.80 \mathrm{mg} / \mathrm{l}$, respectively, which demonstrated the pollution conditions of the river water. At the middle reach of the Suzu River, there is a municipal wastewater treatment plant (WWTP) discharging secondary effluent into the Suzu River. Just downstream from the WWTP outfall is a dam where water, containing secondary effluent, has been withdrawn for irrigation during agricultural seasons. The toxicity contribution of the WWTP effluent was significant to deteriorate the downstream water quality as evidenced by two samples (sites $\mathrm{F}$ and G) collected on May 27th which indicated that the blank samples had a certain toxicity (BSRs were ranked as C and D) and the DOCs were 13.85 and $14.81 \mathrm{mg} / \mathrm{l}$, respectively. The above results indicated that water quality was significantly affected by the discharge of household raw sewage and WWTP effluent.

\subsection{The effects of herbicides using on BSR and DOC}

In the study area of the Hinata River, the water samples were collected before and after the herbicides application season, as shown in Fig. 2, the BSR of water sample at site $C$ decreased from rank A to rank B after the application of herbicides, while the BSR of site B had no apparent change due to small paddy field, about $2000 \mathrm{~m}^{2}$, in which small quantities of herbicides were applied. The DOCs values for both sites B and C were slightly decreased after the herbicides application, which might be attributed to the higher water flow of the Hinata River in June than that in May.

In the study area of the Shibuta River (Fig. 3), by comparing the BSRs of water samples collected at site D and E, it was observed that the growth inhibition rate of algae test obviously increased after herbicides application, and the toxicity scores increased from 2 to 4 and from 1 to 4 for samples on site D and E, respectively. This results were consistent with other study findings (Otsuka and Kawahara, 2005), which showed that some herbicides such as thiobencarb, mefenacet, simetryne were applied in the studied area and $\mu \mathrm{g} / \mathrm{l}$ level of them were detected from nearby water with a frequency of $>60 \%$. However, the DOCs of two water samples (sites D and $\mathrm{E}$ ) on June 8 th reduced to 8.15 and $10.66 \mathrm{mg} / \mathrm{l}$, attributable to increase in water flow.

In the study area of the Suzu River (Fig. 4), two samples results (sites $\mathrm{F}$ and $\mathrm{G}$ ) collected on June 8th were significantly different: BSRs deteriorated from rank B to D, in which all of the three toxicity scores deteriorated significantly, e.g. both of the toxicity scores for the algae and daphnia tests elevated from 2 to 4 , and increased from 2 to 3 for medaka test. It was noted that DOCs values on June 8th, also elevated from 9.08 to $15.29 \mathrm{mg} / \mathrm{l}$, and there was a small decrease comparing with the values on May 27th, but the decrease was not significant because the WWTP effluent contributes a large share to the Suzu River related to that of herbicides.

\subsection{The effects of insecticides using on BSR and DOC}

In the study area of the Hinata River, the water samples collected on July 22nd and August 3rd, are shown in Fig. 2, all of the BSRs of water samples at sites $B$ and $C$ were ranked as $A$. The information obtained from on-site investigation and responses from local peasants showed that insecticides were hardly applied in the studied area due to less necessity. No change of DOCs values for each sampling date at both sites B and C was observed.

In the study area of the Shibuta River (shown in Fig. 3), considering the BSRs of water samples collected at sites D and E before and after the insecticides application season, it was noted that the toxicity scores of daphnia test for all samples were 4 , which were attributed to the low coverage of sewage service within the 
Table 1

The values of DOCs and BSRs for tested water samples

\begin{tabular}{|c|c|c|c|c|c|c|c|c|}
\hline \multirow[t]{2}{*}{ Sampling date } & \multirow[t]{2}{*}{ Test results } & \multicolumn{3}{|c|}{ Hinata River } & \multicolumn{2}{|c|}{ Shibuta River } & \multicolumn{2}{|c|}{ Suzu River } \\
\hline & & Site A & Site B & Site C & Site D & Site E & Site F & Site G \\
\hline \multirow[t]{2}{*}{ April 29th } & $\mathrm{DOC}(\mathrm{mg} / \mathrm{l})$ & 2.99 & 2.44 & 2.52 & 21.15 & 35.80 & 1 & 1 \\
\hline & $\mathrm{BSR}(\mathrm{A}, \mathrm{D}, \mathrm{M})^{*}$ & $\mathrm{~A}(1,1,1)$ & $\mathrm{A}(1,1,1)$ & $\mathrm{A}(1,1,1)$ & $\mathrm{D}(2,4,3)$ & $\mathrm{D}(1,4,2)$ & i & i \\
\hline \multirow[t]{2}{*}{ May 27th } & DOC (mg/l) & 1 & 3.55 & 3.35 & 1 & 1 & 13.85 & 14.81 \\
\hline & $\mathrm{BSR}(\mathrm{A}, \mathrm{D}, \mathrm{M})^{*}$ & i & $\mathrm{A}(1,1,1)$ & $\mathrm{A}(1,1,1)$ & I & i & $C(2,3,2)$ & $\mathrm{D}(1,4,1)$ \\
\hline \multirow[t]{2}{*}{ June 8th } & $\mathrm{DOC}(\mathrm{mg} / \mathrm{l})$ & 1 & 2.01 & 1.50 & 8.15 & 10.66 & 9.08 & 15.29 \\
\hline & $\mathrm{BSR}(\mathrm{A}, \mathrm{D}, \mathrm{M})^{*}$ & I & $\mathrm{A}(1,1,1)$ & $\mathrm{B}(2,1,1)$ & $\mathrm{D}(4,4,2)$ & $\mathrm{D}(4,4,2)$ & $\mathrm{B}(2,2,2)$ & $\mathrm{D}(4,4,3)$ \\
\hline \multirow[t]{2}{*}{ July 22nd } & $\mathrm{DOC}(\mathrm{mg} / \mathrm{l})$ & I & 0.77 & 0.46 & 3.56 & 4.79 & 6.80 & 2.64 \\
\hline & $\mathrm{BSR}(\mathrm{A}, \mathrm{D}, \mathrm{M})^{*}$ & i & $\mathrm{A}(1,1,1)$ & $\mathrm{A}(1,1,1)$ & $\mathrm{D}(1,4,1)$ & $\mathrm{D}(1,4,2)$ & $C(2,3,2)$ & $\mathrm{D}(1,4,2)$ \\
\hline \multirow[t]{2}{*}{ August 3rd } & DOC (mg/l) & 1 & 1.13 & 1.25 & 2.93 & 1.69 & 2.72 & 1.63 \\
\hline & $\mathrm{BSR}(\mathrm{A}, \mathrm{D}, \mathrm{M})^{*}$ & i & $\mathrm{A}(1,1,1)$ & $\mathrm{A}(1,1,1)$ & $\mathrm{D}(1,4,2)$ & $\mathrm{D}(1,4,1)$ & $\mathrm{B}(1,2,1)$ & $\mathrm{D}(1,4,1)$ \\
\hline
\end{tabular}

BSR(A,D,M) means BSR(toxicity scores of algae test, daphnia test, medaka test).

study area (as shown in Fig. 1) where some domestic chemicals e.g. surfactants were discharged into nearby river water. Moreover, some insecticides, e.g. diazinon, fenitrothion were applied in this area (Otsuka and Kawahara, 2005). In addition, Fig. 3 also showed that the toxicity scores of medaka test reduced from 2 to 1 for the sample collected on August 3rd, because the ditch water was diluted due to increase water level in downstream river after heavy rain. Similarly, the corresponding DOCs had a decrease as well.

In the study area of the Suzu River (Fig. 4), the two samples of sites F and $G$ were collected on July 22nd and August 3rd, and the results indicated that the BSRs increased from rank $\mathrm{C}$ to rank $\mathrm{D}$ and from rank B to rank D, respectively after the water flowed through the paddy field, in which the toxicity scores for daphnia test had great changes due to the presence of insecticides in the ditch water. The DOC values for the water samples had a small decrease, from 6.80 to $2.64 \mathrm{mg} / \mathrm{l}$ on site $\mathrm{F}$, from 2.72 to $1.63 \mathrm{mg} / \mathrm{l}$ on site $\mathrm{G}$.

\subsection{The comparison of BSR and DOC for water samples}

DOC has been commonly used as one of important indices for evaluating water pollution, which reflects the total dissolved organic pollutants in the water. However, since more and more toxic organic chemicals have been found in water, the index DOC is no longer sensitive enough for water quality protection. Although DOC in water can be analyzed easily, it cannot provide the real toxicity of the organic pollutants. On the other hand, although the developed toxicity index BSR is somewhat complicated to deter-

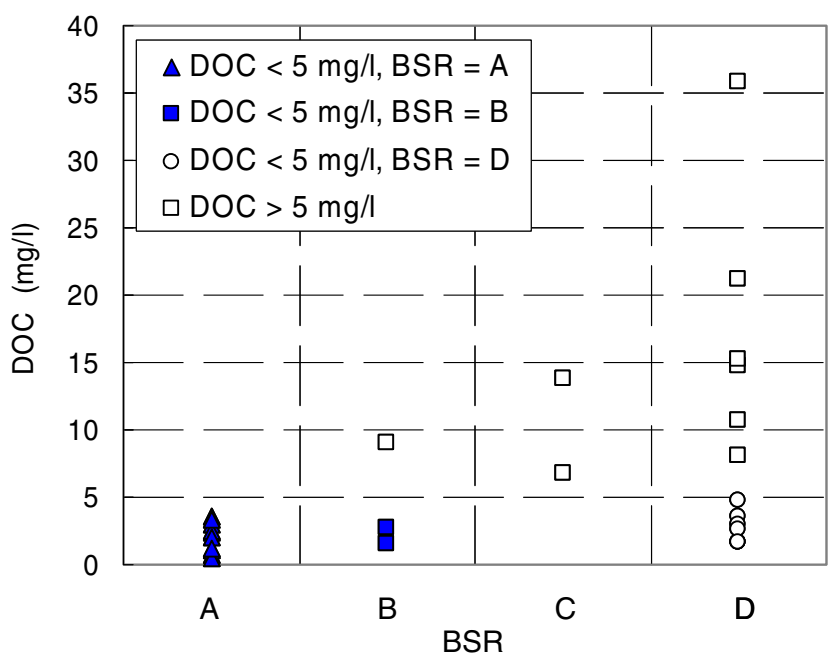

Fig. 5. BSR verses DOC in study areas. mine compared to DOC, it is still a feasible index to reflect the overall toxicity of the organic pollutants in river water. As shown in Table 1, water samples with high DOC concentrations tended to relate to high toxicity values; however, a low DOC concentration did not always represent low toxicity. In other words, a large variation of BSR could be observed against a low DOC concentration, a plot of BSRs versus DOCs of studied samples is shown in Fig. 5. As shown in this study, for example, BSR could range from rank A to D and toxicity score could range from 1 to 4 within corresponding DOC ranges from 2 to $3 \mathrm{mg} / \mathrm{l}$. It was therefore concluded that BSR could be an effective bio-safety index for evaluating water quality.

In order to check the correlation of BSRs and DOCs of studied samples, a Chi-square test was conducted by using Crosstab method of SPSS software package because BSR is a categorical classification variable. The numerical variable DOC was changed into a categorical variable according to more than or less than $5 \mathrm{mg} / \mathrm{l}$ of DOC values, and the frequency distribution of BSRs is shown in Table 2. Fisher's Exact Module was used to test the correlation of two variables DOC and BSR, and the results are shown in Table 3. The contingency coefficient of test was 0.529 , both of the Phi and Cramer's V was 0.624 , and the Gamma value was -0.710 . All these output of statistical implied that there was a certain correlation between DOCs and BSRs although it was not significant, so the conventional water quality index DOC cannot be used directly to predict BSR. Some other researches also observed that the median lethal concentration ratio (LCR50) was not closely dependent on the common water quality indicator of DOC (Liu et al., 2007), and the combination of chemical methods with biological/ toxicological methods could be very useful in estimating the risk

Table 2

Cross tabulation for the studied samples

\begin{tabular}{lllllll}
\hline & & \multicolumn{2}{l}{ Frequency of BSR } & & Total \\
\cline { 3 - 6 } & & A & B & C & D & \\
\hline \multirow{2}{*}{ DOC } & $>5(\mathrm{mg} / \mathrm{l})$ & 0 & 1 & 2 & 6 & 9 \\
\multirow{2}{*}{ Total } & $<5(\mathrm{mg} / \mathrm{l})$ & 10 & 2 & 0 & 6 & 18 \\
& & 10 & 3 & 2 & 12 & 27 \\
\hline
\end{tabular}

Table 3

The results of Chi-square tests by using crosstab method

\begin{tabular}{lllll}
\hline & Value & d.f. & Asymp. Sig. (2-sided) & Exact Sig. (2-sided) \\
\hline Pearson Chi-square & 10.500 & 3 & 0.015 & 0.008 \\
Likelihood ratio & 13.917 & 3 & 0.003 & 0.005 \\
Fisher's exact test & 10.581 & $/$ & $/$ & 0.005
\end{tabular}

d.f.: degree of freedom. 
of contaminants and contaminated environmental elements (Fent, 2003; Tsui and Chu, 2003).

\section{Conclusion}

In this study, the newly established method was used to evaluate the effects of human activities on the bio-safety of water quality, and the results indicated that the evaluation method based on the toxicity test set composing of algae growth inhibition test, daphnia magna immobilization test and larval medaka lethal test was very effective and sensitive, and it could successfully reveal the release of toxic chemicals into river water. From the results, it was apparent that the river water quality near agricultural areas was deteriorated by agricultural activities, such as pesticides application. In addition, the low coverage of sewage service area could exert significant impact on nearby streams, due to presence of some domestic chemicals in raw sewage which appeared to be toxic to aquatic organisms, e.g. daphnia magna. Fortunately, the developed evaluation indices, e.g. toxicity score and BSR, can vividly reflect the properties of toxic pollutants which are agreeable with the chemical analyses results reported by other researchers although there was no significant quantitative relationship with the conventional water quality index DOC. The established method could be used as a useful and practical screening tool for prioritizing some polluted areas for environmental management. As for the Kaname River, counter-measures to improve the water quality should be proposed especially for the pesticides application season, which would be regarded as an example for management of other river basins.

\section{Acknowledgements}

This study was partly supported by National Key Technologies R\&D Program (2007BAC22B02) and National High-Tech R\&D Program (2007AA06Z338), MOST, PR China, 21st Century COE Program Environmental Risk Management for Bio-Eco Systems, MEXT, Japan. The authors would like to thank Mr. James Wang (USA) for his valuable advices and constructive comments.

\section{References}

Asakura, H., Matsuto, T., Tanaka, N., 2004. Behavior of endocrine disrupting chemicals in leachate from MSW landfill sites in Japan. Waste Manage. 24, 613-622.

Bekaert, C., Rast, C., Ferrier, V., Bispo, A., Jourdain, M.J., Vasseur, P., 1999. Use of in vitro (Ames and Mutatox tests) and in vivo (amphibian micronucleus test) assays to assess the genotoxicity of leachates from a contaminated soil. Org. Geochem. 30, 953-962.

Bispo, A., Jourdain, M.J., Jauzein, M., 1999. Toxicity and genotoxicity of industrial soils polluted by polycyclic aromatic hydrocarbons (PAHs). Org. Geochem. 30, 947-952.

Daughton, C.G., Ternes, T.A., 1999. Pharmaceuticals and personal care products in the environment: agents of subtle change? Environ. Health Perspect. 107 (Suppl. 6), 907-938.

Fent, K., 2003. Ecotoxicological problems associated with contaminated sites. Toxicol. Lett., 353-365.
Ferard, J.F., Ferrari, B., 2005. Wastoxhas: a bioanalytical strategy for solid wastes assessment: a review. In: Blaise, C., Ferard, J.F. (Eds.), Small-Scale Freshwater Toxicity Investigation: Volume 2-Hazard Assessment Schemes. Springer, Secaucus, NJ, pp. 331-375.

Fernandez, M.D., Cagigal, E., Vega, M.M., Urzelai, A., Babin, M., Pro, J., Tarazona, J.V., 2005. Ecological risk assessment of contaminated soils through direct toxicity assessment. Ecotoxicol. Environ. Saf. 62, 174-184.

Halling-Sorensen, B., Nielson, S.N., Lanzky, P., Ingerslev, F., Holten, L.J., Jorgensen, S.E., 1998. Occurrence, fate and effects of pharmaceutical substances in the environment - a review. Chemosphere 36 (2), 357-394.

Hanada, Y., Imaizumi, I., Kido, K., Tanizaki, T., Koga, M., Shiraishi, H., Soma, M., 2002. Application of a pentafluorobenzyl bromide derivatization method in gas chromatography/mass spectrometry of trace levels of halogenated phenols in air, water and sediment samples. Anal. Sci. 18, 655-659.

Hasegawa, A., Suzuki, S., 2005. Analysis of chemical substances in the leachate of landfill by LC/MS. B. Kanagawa. Environ. Res. Cent. 28, 45-51 (in Japanese).

Hernando, M.D., Fernández-Alba, A.R., Tauler, R., Barceló, D., 2005. Toxicity assays applied to wastewater treatment. Talanta 65 (2), 358-366.

Ishii, S., Urano, K., Kameya, T., 2000. General conditions for concentrating trace organic compounds in water with porous polystyrene cartridges. J. Jpn. Soc. Wat. Environ. 23, 85-92 (in Japanese).

Juvonen, R., Martikainen, E., Schultz, E., Joutti, A., Ahtiainen, J., Lehtokari, M., 2000. A battery of toxicity tests as indicators of decontamination in composting oily waste. Ecotoxicol. Environ. Saf. 47, 156-166.

Kimerle, R., Barnthouse, L., Brown, R., de Beyssac, B.C., Gilbertson, M., Monk, K., Poremski, H.J., Purdy, R., Reinert, K., Rolland, R., Zeeman, M., 1997. Ecological effects. In: Wanson, M.B., Socha, A.C. (Eds.), Chemical Ranking and Scoring Guidelines for Relative Assessments of Chemical: Proceedings of the Pellston Workshop on Chemical Ranking and Scoring, 11-16 February 1995, Sandestin, Florida: Pensacola, FL., SETAC Press, SETAC special publication series, p. 154 (Chapter 4).

Kondo, F., Matsumoto, H., Yamada, S., Tsuji, K., Ueno, Y., Harada, K., 2000 Immunoaffinity purification method for detection and quantification of microcystins in lake water. Toxicon $38,813-823$.

Liu, R., Kameya, T., Sawai, A., Urano, K., 2007. Application of a larval medaka assay to evaluate the fish safety level in Sagami River, Japan. Environ. Monit. Assess. 130, 475-482.

Munn, M.D., Gilliom, R.J., 2001. Water-resources investigations report 01-4077: pesticide toxicity index for freshwater aquatic organisms. United States Geological Survey (USGS), Sacramento, CA, pp. 1-61.

Okayama, A., Tanaka, K., Tamaki, M., 1998. Simultaneous liquid chromatographic determination of eight kinds of preservatives and sodium saccharin in foods. Jpn. J. Food Chem. 5, 153-158.

Otsuka, T., Mishima, S., Kawahara, H., 2005. Loadings of PRTR pesticides in Kaname River. In: Proceedings of 39th Annual Conference of Japan Society on Water Environment. 449pp.

Personne, G., Marsalek, B., Blinova, I., Torokne, A., Zarine, D., Manusadzianas, L. Nalecz-Jawecki, G., Tofan, L., Stepanova, N., Tothova, L., Kolar, B., 2003. A practical and user-friendly toxicity classification system with microbiotests for natural waters and wastewaters. Environ. Toxicol. 18, 395-402.

Rila, J.P., Eisentraeger, A., 2003. Application of bioassays for risk characterization and remediation control of soils polluted with nitroaromatics and PAHs. Water Air Soil Pollut. 148, 223-242.

Sudo, M., Kunimatsu, T., Okubo, T., 2002. Concentration and loading of pesticide residues in Lake Biwa basin (Japan). Wat. Res. 36, 315-329.

Tanabe, A., Kawata, K., 2004. Determination of triazine pesticides and related compounds in environmental water by liquid chromatography-mass spectrometry. Anal. Sci. 20, 227-230.

Tanabe, A., Mitobe, H., Kawata, K., Sakai, M., Yasuhara, A., 2000. New monitoring system for ninety pesticides and related compounds in river water by solidphase extraction with determination by gas chromatography/mass spectrometry. J. AOAC Int. 83, 61-77.

Tsui, M.T.K., Chu, L.M., 2003. Aquatic toxicity of glyphosate-based formulations: comparison between different organisms and the effects of environmental factors. Chemosphere 52, 1189-1197.

Wei, D.B., Kisuno, A., Kameya, T., Urano, K., 2006. A new method for evaluating biological safety of environmental water with algae, daphnia and fish toxicity ranks. Sci. Tot. Environ. 371, 383-390. 